\title{
Self medication among elderly poses challenges in urban settings
}

\author{
Sadhana K. Hingorani ${ }^{1 *}$, Anupama S. Desai ${ }^{1}$, Sakshi S. Desai ${ }^{2}$, Raj Kumar Bansal ${ }^{3}$, \\ Shubham Agarwal ${ }^{4}$, Naisargee Solanki ${ }^{4}$, Ishaan Desai ${ }^{5}$
}

\author{
${ }^{1}$ Department of Pharmacology, ${ }^{3}$ Department of PSM, ${ }^{4}$ SMIMER, Surat, Gujarat, India \\ ${ }^{2}$ Neurogen Brain and Spine Institute, Navi Mumbai, Maharashtra, India \\ ${ }^{5}$ Department of Medicine, Smt. NHLMMC Ahmedabad, Gujarat, India
}

Received: 07 March 2021

Revised: 07 April 2021

Accepted: 09 April 2021

\section{*Correspondence:}

Dr. Sadhana K. Hingorani,

Email: nishant1t05@gmail.com

Copyright: ( ) the author(s), publisher and licensee Medip Academy. This is an open-access article distributed under the terms of the Creative Commons Attribution Non-Commercial License, which permits unrestricted non-commercial use, distribution, and reproduction in any medium, provided the original work is properly cited.

\begin{abstract}
Background: Self-medication can be defined as obtaining and consuming one (or more) drug(s) without the advice of a physician. Using over the counter medicine is a common practice in developing countries including India. Studies have shown relatively high rates of self-medication among elderly and suggested awareness programmes among this group. Objectives of current study are to determine the prevalence of self-medication among geriatric population and to educate them about self-medication by an interactive session.

Methods This was a cross sectional, questionnaire based study to evaluate the prevalence of self-medication in geriatric population in senior citizen club of Adajan and Ghoddod area of Surat city. Questionnaires were designed and modified from previous studies. Written informed consent was taken from those willing to participate in the study. After filling of pre-questionnaire, an interactive session was arranged and post-questionnaire were given to all participants. Data obtained were subjected to statistical analysis.

Results: Number of participants in present study was 100. Self-medication was most common in age group of 65 to 75 years $(48 \%)$ followed by less than 65 years (33\%). 85\% participants reported having taken non-prescription drugs. Drugs commonly used for self-medication were analgesics (85) and antacids (80). Side effects due to self-medication were reported by 22 participants. Main reasons for self-medication cited were to save expenses (65) and to save time (62). Post study awareness increased to $98 \%$.

Conclusions: Prevalence of self-medication is high in elderly. Interactive session can increase awareness regarding self-medication.
\end{abstract}

Keywords: Self-medication, Elderly, Drugs

\section{INTRODUCTION}

Self-medication can be defined as obtaining and consuming one (or more) drug(s) without the advice of a physician. ${ }^{1}$ Self-medication with over-the-counter (OTC) drugs is an economical choice of treatment for common illnesses. The tendency of using over the counter (OTC) medicine is a common practice in developing countries and WHO has regarded self-medication as a part of selfcare. $^{2,3}$ In developing countries including India, a wide range of medications are easily available without prescriptions.

Ageing is associated with various health related problems like arthritis, diabetes, hypertension, Alzheimer's etc. This is a common reason that polypharmacy is seen more 
in the geriatric population. This age group is also likely to have more complications like renal, hepatic, GIT related toxicities compared to other age groups. Studies have shown relatively high rates of self-medication among elderly age groups and have suggested awareness programmes among this group.,

\section{Aim and objectives}

Current study aims to determine the prevalence of selfmedication among geriatric population. Objectives of the current study were to know what the common drugs are and to assess the common reasons for self-medication, to assess change in awareness and impact of awareness programme on self-medication.

\section{METHODS}

This was a cross sectional, questionnaire based study to evaluate the prevalence and awareness regarding selfmedication. Persons of age more than 60 years residing in Surat city (senior citizen clubs/parks in Ghoddod and Adajan areas) were taken for this study. Sample size comprised of all elderly who could be covered in a survey period comprising of 3 months' duration (1 March 2017 to 30 May 2017). Age more than 60 years and participants willing to participate were included in the study where as participants not willing to participate and age less than 60 years were excluded from current study. Statistical analysis was done using Chi square test, and other suitable tests.

Questionnaires were designed and modified from previous studies. ${ }^{2,4}$ Briefing was given about the nature of study, and the procedure of completing the questionnaire was explained. Written informed consent is taken from those who were willing to participate in the study. Prequestionnaire were given to all participants. An interactive session was arranged followed by postquestionnaire. As some of the questions had multiple options to choose from, the sum of percentage did not always add up to $100 \%$.

\section{RESULTS}

Number of participants who completed the questionnaire in our study were 100. Majority of the participants were male $(60 \%)$ as compared to female $(40 \%)$ (Table 1$)$.

Table 1: Gender wise distribution of participants $(\mathrm{n}=100)$.

\begin{tabular}{|lll|}
\hline Gender & N & $(\%)$ \\
\hline Male & 60 & 60 \\
\hline Female & 40 & 40 \\
\hline Total & 100 & 100 \\
\hline
\end{tabular}

Self-medication was most common in less than 65 years of age (100\%), followed by $65-75$ years $(95.8 \%)$ and
$94.7 \%$ in above 75 years of age (Table 2). Out of 100 participants $28 \%$ were illiterate, $21 \%$ were educated up to high school, $41 \%$ were graduates, $2 \%$ were post graduate. In our study $85 \%$ were retired and $15 \%$ were working in private sectors. Ninety-seven percent were married and $3 \%$ were unmarried (Figure 1).

Table 2: Distribution according to age group $(n=100)$.

\begin{tabular}{|lcc|}
\hline Age group (years) & $\mathbf{N}$ & $(\%)$ \\
\hline$<\mathbf{6 5}$ & 33 & 100 \\
\hline $\mathbf{6 5 - 7 5}$ & 48 & 95.8 \\
\hline$>\mathbf{7 5}$ & 19 & 94.7 \\
\hline
\end{tabular}

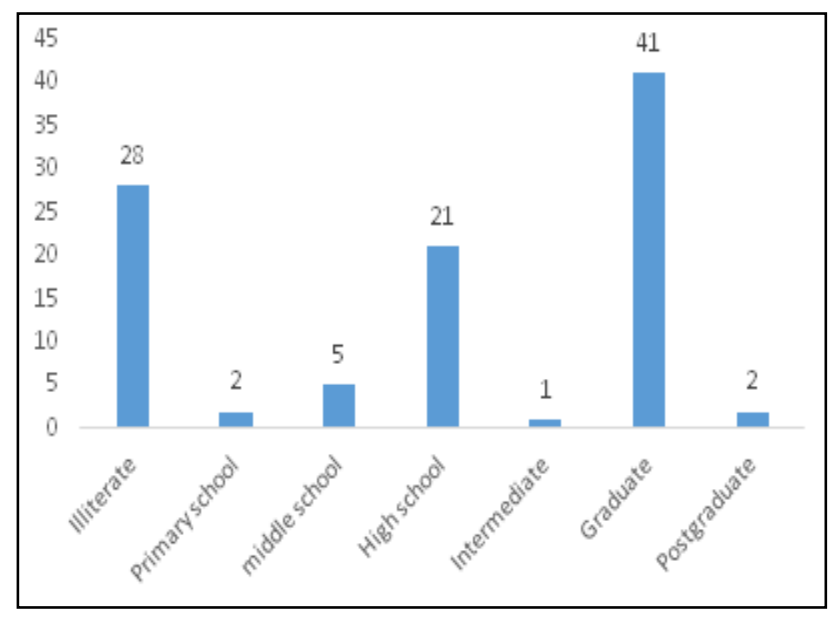

Figure 1: Educational status of participants.

Fifty-seven percent of the study group did not go for health check-up and $43 \%$ of them went for regular health check-up. $39 \%$ of them exercised daily for fitness while $40 \%$ reported not doing any exercise (Table 3 ). In the study $38 \%$ always discussed health issues, $28 \%$ discussed sometimes and $21 \%$ of them rarely discussed with their friends. $13 \%$ percent reported that they never discussed health related issues with their friends (Table 4).

Table 3: Participants doing exercise $(n=100)$.

\begin{tabular}{|lll|}
\hline Exercise & N & $(\%)$ \\
\hline Daily & 39 & 39 \\
\hline off and on & 7 & 7 \\
\hline Rarely & 14 & 14 \\
\hline Never & 40 & 40 \\
\hline Total & 100 & 100 \\
\hline
\end{tabular}

Table 4: Discussion of health related issues $(n=100)$.

\begin{tabular}{|lcc|}
\hline Discussion of health issues & $\mathbf{N}$ & $(\boldsymbol{\%})$ \\
\hline Always & 38 & 38 \\
\hline Sometimes & 28 & 28 \\
\hline Rarely & 21 & 21 \\
\hline Never & 13 & 13 \\
\hline
\end{tabular}


In current study $85 \%$ have reported consuming nonprescription drugs, $15 \%$ of participants had never used drugs without prescription (Table 5), 72\% had repeated drugs prescribed earlier to them for similar conditions and $57 \%$ had taken drugs prescribed to their relatives or friends for similar conditions previously. Seventy eight percent reported that they were able to get nonprescription drugs easily while $22 \%$ reported that they did not get drugs without prescription easily. $65 \%$ reported that they took advice from the chemist/pharmacist for minor ailments. $51 \%$ of them reported that chemists/pharmacists don't give advice regarding medicines until they ask for it while $49 \%$ stated that their chemists/pharmacists give advice regarding medicine even when not asked for. The most commonly used drugs for self-medication were analgesics (85\%) followed by antacids $(80 \%)$, cough syrups $(32 \%)$, drugs for insomnia (29\%) multivitamin (16\%) etc (Figure 2).

Table 5: Medicines used without prescription $(n=100)$.

\begin{tabular}{|lll|}
\hline Responses & $\mathbf{N}$ & $(\%)$ \\
\hline Yes & 85 & 85 \\
\hline No & 15 & 15 \\
\hline
\end{tabular}

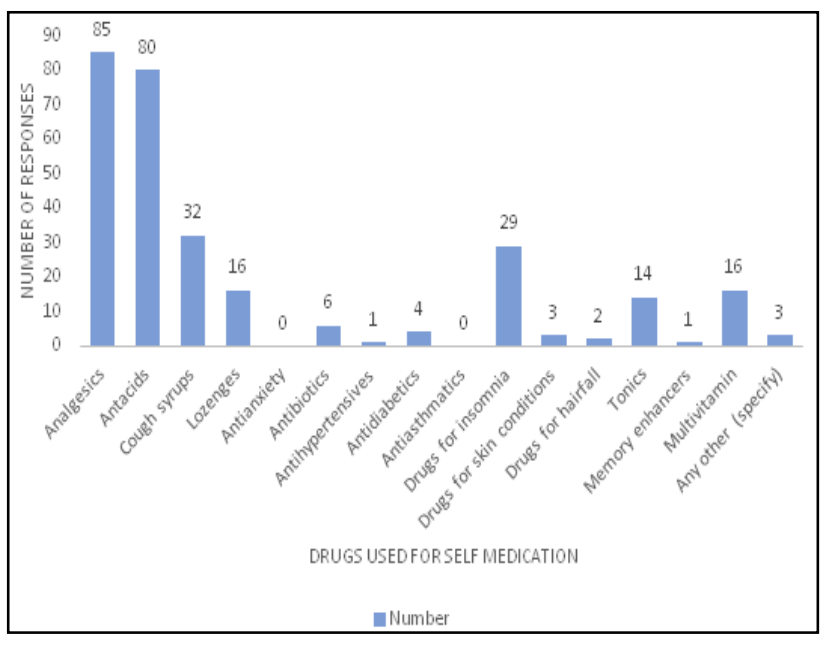

Figure 2: Drugs for self-medication by participants.

Majority $(78 \%)$ of them never had any side effects due to self-medication and $22 \%$ reported having side effects. On suffering from side effects $58 \%$ stop the medicines, $29 \%$ go to doctor, $5 \%$ ask their friends /relatives and $5 \%$ of them find their solution on internet, $1 \%$ go back to chemist. $73 \%$ were taking alternate medicines like ayurvedic $(50 \%)$, homeopathic $(36 \%)$, naturopathy $(5 \%)$, others (9\%) (Figure 3). Some participants were using herbal products like tablet/capsules (32), juices (13), chawanprash (18), others like powders (8). 32\% had not informed their doctor about alternative products they were taking while $68 \%$ of them had informed their doctor about the same.

Source of self-medication in study was advertisement $(41 \%)$, word of mouth by friends/relatives $(30 \%)$, doctors
(12\%), brochures (2\%), and internet (1\%) (Figure 4). Supplementations like multivitamins were taken by 76 of them, iron (48), vitamin D (5) and three of them were taking vitamin B-12. Reasons for self-medication were to save expenses (65), to save time (62), not wishing to trouble family members (42), feeling it is not a serious condition (12), not having someone to accompany them to the doctor (7) and dissatisfaction with doctor's treatment in past (2) (Figure 5).

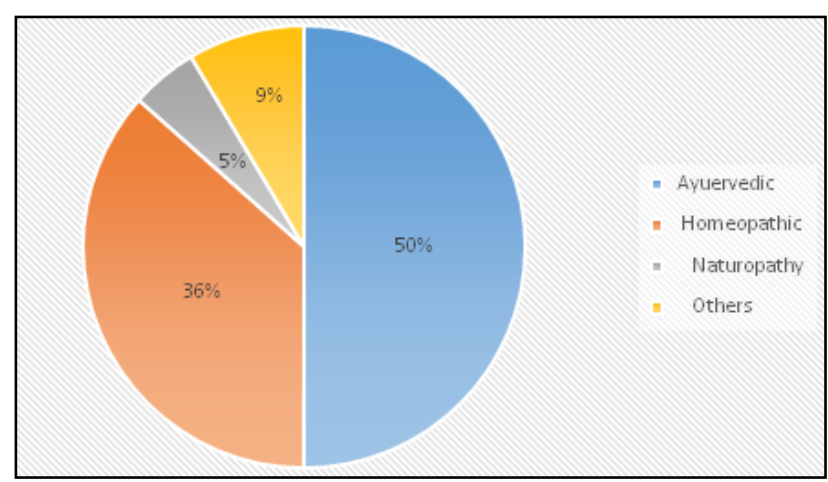

Figure 3: Alternative medicines used by participants $(n=73)$.

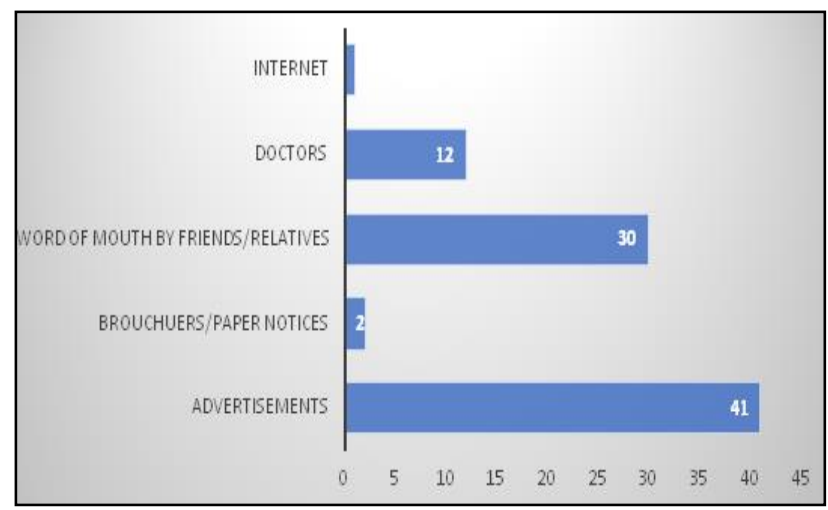

Figure 4: Source of information about selfmedication.

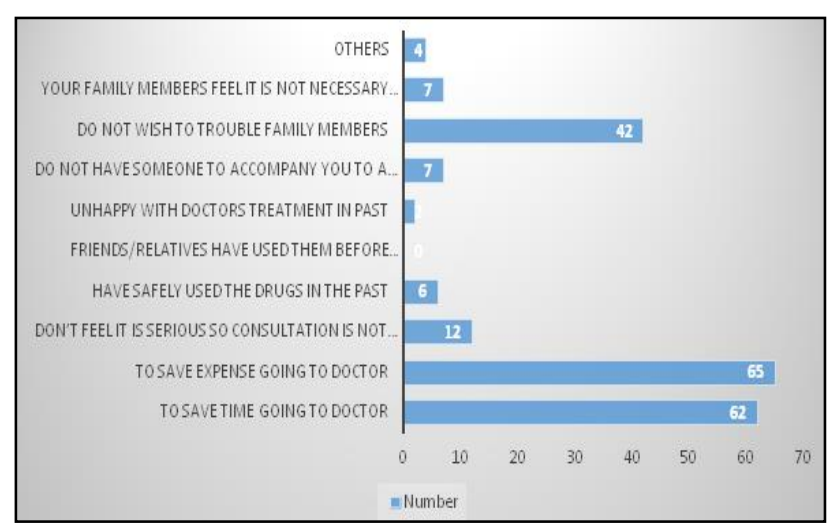

Figure 5: Reasons for self-medication.

Before the sensitization programme $94 \%$ of them were not aware about OTC drugs. After training $100 \%$ of them 
were aware about OTC drugs. Regarding awareness about problems due to self-medication, $77 \%$ were not aware before the sensitization programme which increased to $(98 \%)$ after the session, $1 \%$ were not sure and $1 \%$ not aware about these problems even after the session. Prior to the session $94 \%$ of them wanted to know more about self-medication. After the session $100 \%$ felt that the session was helpful. All reported that they would pass this message on to their family and friend circle. All of them were of opinion that such training sessions would help spread awareness about self-medication.

\section{DISCUSSION}

Self medication is common in especially elderly population similar results were seen in current study. ${ }^{4,5}$ Present study reported that consumption of non prescription drug was $85 \%$ which is similar to study conducted by Jerez et al. ${ }^{6}$ Seventy two percent of them repeated the drugs prescribed to them in past for similar conditions as seen in study of Sunder et al. ${ }^{1}$ Selfmedication is more common in males $(60 \%)$ in comparison to females $(40 \%)$ these results are similar to other study conducted by Jaferi et al. ${ }^{4}$ Study carried out by Arries et al ${ }^{7}$ showed that analgesics were most commonly used drugs for self-medication similar results were seen in current study. Source of information for self -medication in our study was advertisement (41\%) followed by word of mouth by friends/relatives (30\%) Most common reason for self-medication was to save expenses and to save time similar to study conducted by Ahmed et al in 2015. ${ }^{8}$

Self-medication is common in especially educated and urban settings. ${ }^{9,10}$ All over the world, similar results were seen in our study. Current study reported $73 \%$ of participants took alternate medicine like ayurvedic $(50 \%)$, homeopathic (36\%), naturopathy $(5 \%)$ which is different from other study which shows $69.6 \%$ were taking allopathic drugs. ${ }^{1}$ Results of current study was supported by other studies.., 10 As present study was done in two areas of Surat city further studies are needed in other areas of Surat city to increase awareness and education about self-medication.

\section{CONCLUSION}

Prevalence of self-medication is high in elderly. After sensitization programme, the awareness regarding selfmedication has increased. Considering that polypharmacy is prevalent in geriatric population several such sensitization sessions need to be held to increase awareness and education about self-medication.
Funding: No funding sources Conflict of interest: None declared

Ethical approval: The study was approved by the Institutional Ethics Committee

\section{REFERENCES}

1. Keshari SS, Kesarwani P, Mishra M. Prevalence and pattern of self-medication practices in rural area of Barabanki. Indian J Clin Prac. 2014;25:7-12.

2. Mahmood A, Kushtiwala DH. Self-medication and inappropriate drug use in geriatric population of Karachi, Pakistan. J Dent Med Sci. 2014;13(11):6671.

3. Bertoldi AD, Camargo AL, Silveira MPT, Menezes A, Assuncao MCF, Goncalves $H$, et al. Selfmedication among adolescents aged 18 years: the 1993 Pelotas (Brazil) Birth Cohort Study. J Adol Health. 2014;55(2):175-81.

4. Jafari F, Khatony A, Rahmani E. Prevalence of selfmedication among the elderly in Kermanshah-Iran. Glob J Health Sci. 2015;7(2):360-5.

5. Karimy M, Heidarnia AR , Ghofranipour F. Factors influencing self-medication among elderly urban centers in Zarandieh based on health belief model. Arak Med Univ J. 2015;5:15-9.

6. Jerez-Roig J, Medeiros LF, Silva VA, Bezerra CL, Cavalcante LA, Piuvezam G, Souza DL. Prevalence of self-medication and associated factors in an elderly population: a systematic review. Drugs Aging. 2014;31(12):883-96.

7. Arrais PS, Coelho HL, Batista Mdo C, Carvalho ML, Righi RE, Arnau JM. Profile of self-medication in Brazil. Rev Saude Public. 1997;31(1):71-7.

8. Ahmad A, Khan MU, Srikanth AB, Kumar B, Singh NK. Evaluation of knowledge, attitude and practice about self-medication among rural and urban North Indian Population. Int $\mathbf{J}$ Pharma Clin Res. 2015;7(5):326-32.

9. Zafar SN, Syed R, Waqar S, Zubairi AJ, Vaqar T, Shaikh M, et al. Self-medication amongst university students of Karachi: prevalence, knowledge and attitudes. J Pak Med Assoc. 2008;58(4):214.

10. Sanghani S, Zaveri HG, Patel VJ. Self-medication: prevalence and pattern in urban community. J Pharmacovigil Drug Safe. 2008;5:95-8.

Cite this article as: Hingorani SK, Desai AS, Desai SS, Bansal RK, Agarwal S, Solanki N, et al. Self medication among elderly poses challenges in urban settings. Int J Basic Clin Pharmacol 2021;10:541-4. 